\title{
ESTIMASI CADANGAN BATUBARA DENGAN SOFTWARE TAMBANG PADA PIT DE DISITE BEBATU PT. PIPIT MUTIARA JAYA KABUPATEN TANA TIDUNG, KALIMANTAN UTARA
}

\author{
A.A Inung Arie Adnyano \\ Dosen Teknik Pertambangan STTNAS Yogyakarta \\ arie adnvana $a$ vahoo.com
}

\begin{abstract}
Abstrak
Lokasi penambangan PIT DE PT. Pipit Mutiara Jaya, Site Bebatu dengan lahan seluas 3.024 Ha terletak di Desa Bebatu Kebun, Kecamatan Sesayap Hilir, Kabupaten Tana Tidung, Provinsi Kalimantan Utara. Metode estimasi yang digunakan yaitu metode sayatan penampang (cross section) yang berdasarkan pada pedoman rule of gradual changes dan rule of nearest point.

Estimasi pedoman rule of gradual changes didapatkan total cadangan terkira adalah 2.605.121,944 ton, volume material gambut adalah $811.218,008 \mathrm{~m}^{3}$, volume material softclay adalah $4.413 .869,289 \mathrm{~m}^{3}$, volume mixing adalah $2.206 .934,637 \mathrm{~m}^{3}$ dan volume material hardclay adalah $11.638 .177,066 \mathrm{~m}^{3}$. Perhitungan berdasarkan pedoman rule of nearest point sebagai berikut: total cadangan terkira adalah $3.047 .878,132$ ton, volume material gambut adalah $918.114,558 \mathrm{~m}^{3}$, volume material softclay adalah $5.040 .942,037 \mathrm{~m}^{3}$, volume mixing adalah $2.520 .471,018 \mathrm{~m}^{3}$ dan volume material hardclay adalah $12.858 .788,961 \mathrm{~m}^{3}$.

Nilai stripping ratio dari hasil kedua perhitungan adalah sebagai berikut: untuk pedoman rule of gradual changes dengan nilai SR 7,32 $\mathrm{BCM}: 1$ ton dan untuk pedoman rule of nearest point dengan nilai SR $7 \mathrm{BCM}: 1$ ton.
\end{abstract}

Kata Kunci: cross section, rule of gradual changes, rule of nearest point, seam, mixing, parting.

\section{Latar Belakang}

Indonesia merupakan salah satu negara yang mempunyai cadangan batubara cukup banyak. Seiring dengan berkurangnya energi minyak dan gas bumi, maka batubara sangat potensial untuk dikembangkan di Indonesia. Bahan bakar ini akan dimanfaatkan sebagai energi lanjutan, seperti energi listrik dan lainnya. Pencarian daerah prospek memerlukan berbagai disiplin ilmu pengetahuan, diantaranya adalah ilmu eksplorasi batubara. Tingkat kepastian cadangan terestimasi menentukan risiko kelayakan ekonomi tambang dan garansi bagi pengembalian modal.

\section{Tujuan Penelitian}

1. Untuk menghitung besarnya cadangan batubara terkira pada PIT DE

2. Untuk menghitung besarnya volume overburden pada PIT DE

3. Untuk menghitung nilai dari stripping ratio

4. Mengetahui perbandingan hasil perhitungan dari metode sayatan penampang

\section{Metodologi Penelitian \\ 1. Pengamatan Lapangan \\ 2. Studi Literatur, karya ilmiah dan laporan penelitian dari perusahaan}


3. Penentuan lokasi dan pengambilan data

4. Pengelompokkan data

a. Data primer: Data logging, data korelasi lubang bor dan titik koordinat lubang bor

b. Data sekunder: lokasi kesampaian daerah, iklim, stratigrafi daerah penelitian dan peta lubang bor

5. Pengolahan data

6. Analisis data

7. Kesimpulan

\section{Lokasi dan Kesampaian Daerah}

Secara administratif, PT. Pipit Mutiara Jaya terletak di Desa Bebatu Kebun, Kecamatan Sesayap Hilir, Kabupaten Tana Tidung, Kalimantan Utara.

Secara geografis, lokasi penambangan berbatasan dengan :

1. Sebelah utara dibatasi Desa Sengkong

2. Sebelah Timur dengan Desa Bebatu Kebun, Desa Supadan Sungai Supa

3. Sebelah Selatan dan Barat dengan Sungai Supa

Secara astronomis, daerah tersebut terletak pada koordinat 117 $\square$ 08' 00" BT - 117 $\square$ 14' 00" BT dan 03 $\square$ 30' 00" LU - 03 $\square$ 38' 00" LU. (Gambar 1)

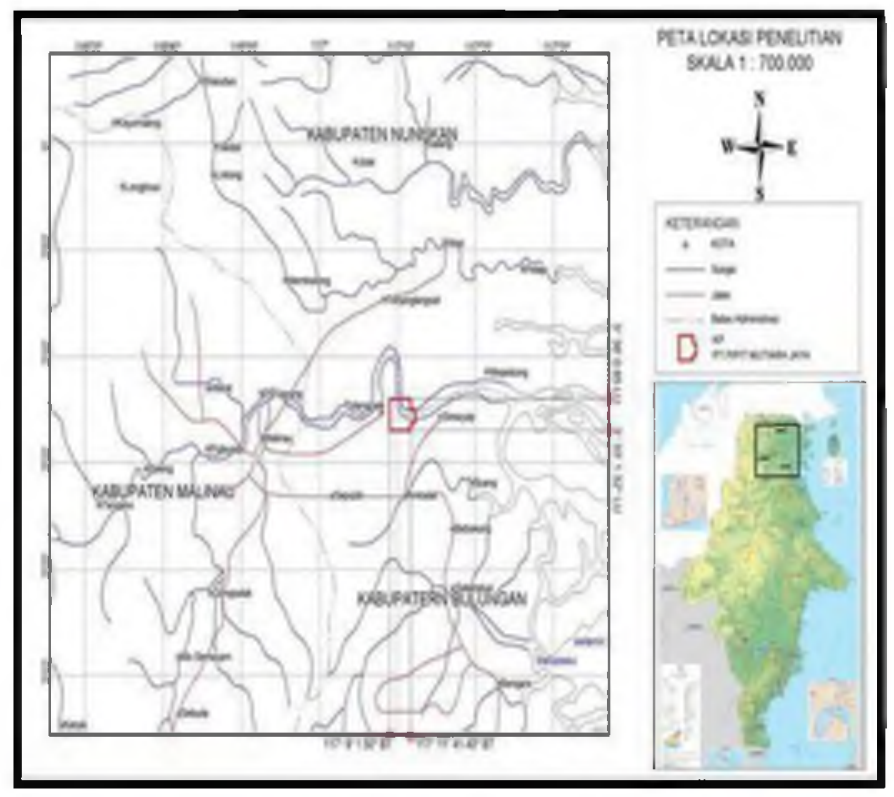

Gambar 1 Peta Lokasi Penelitian (Sumber: Bagian Geologist, PT. PMJ)

\section{Stratigrafi Umum Daerah Pertambangan}

Terdapat di cekungan tarakan dengan dua Formasi yaitu Formasi Tabul dan Formasi Alluvium. Formasi Tabul terdiri dari perselingan batulumpur, batulempung, batupasir dan batugamping. Batubara dibagian atas yang berumur Miosen Atas diendapkan pada lingkungan delta laut dangkal, sedangkan Formasi Aluvium terdiri dari perselingan lumpur, lanau, pasir, kerikil dan koral yang merupakan endapan pantai, sungai dan rawa. Keadaan perlapisan di tambang Site Bebatu terdiri dari lapisan gambut, lapisan batulempung, laisan tanah laterit dan lapisan batupasir (Gambar 2) 


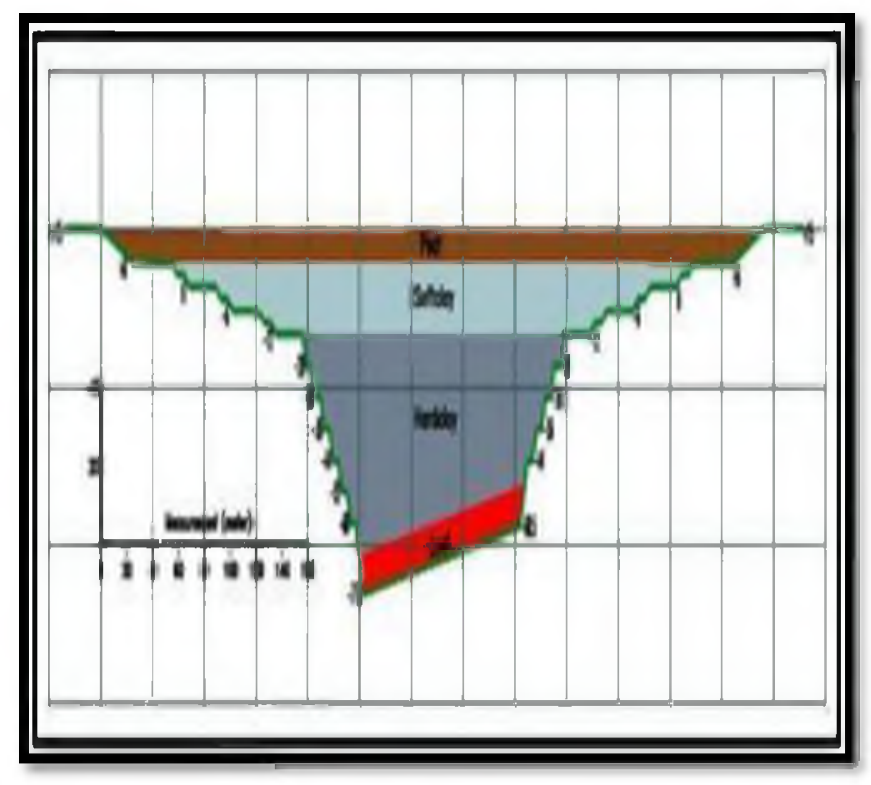

Gambar 2. Litologi di PT. PMJ (Sumber: Bagian Pit Operation, PT. PMJ)

\section{Metodologi Penambangan}

Secaraumum, metode penambangan yang digunakan di PT. Pipit Muitara Jaya, Site Bebatu sama seperti tambang batubara lainnya yaitu metode Open Cut Mining, tetapi karakteristik hamper keseluruhan adalah rawa maka metode ini dikombinasikan dengan metode Cut Fill dengan control Overall Slope untuk proses Stripping Overburden dan Coal Exposenya. (Gambar 3 dan 4)

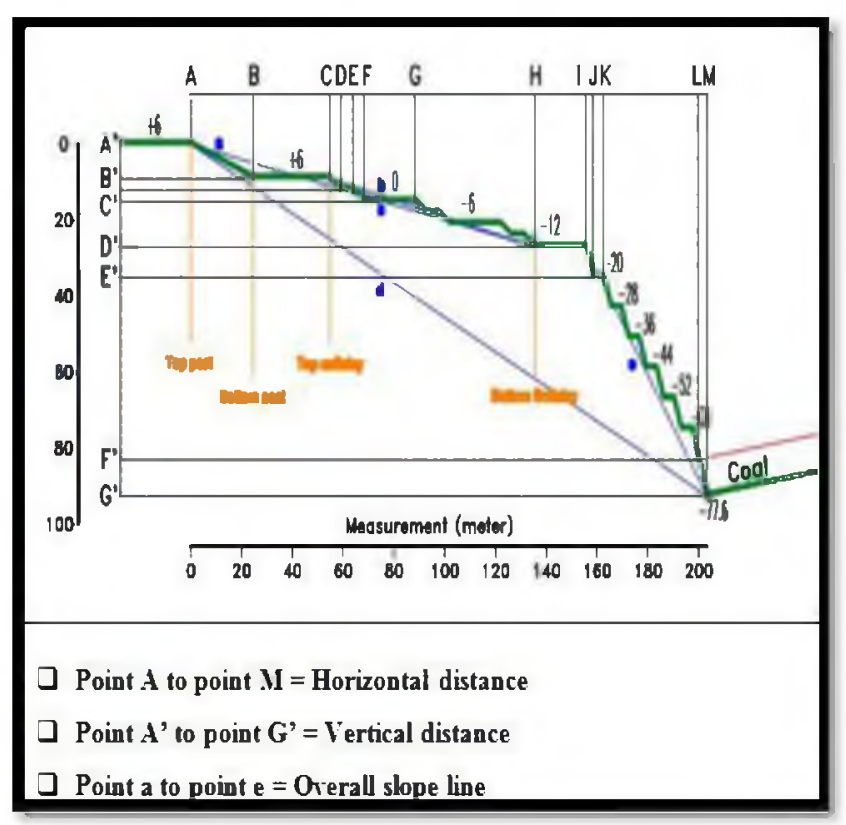

Gambar 3. Overall Slope Method (Sumber: Bagian Pit Operation) 


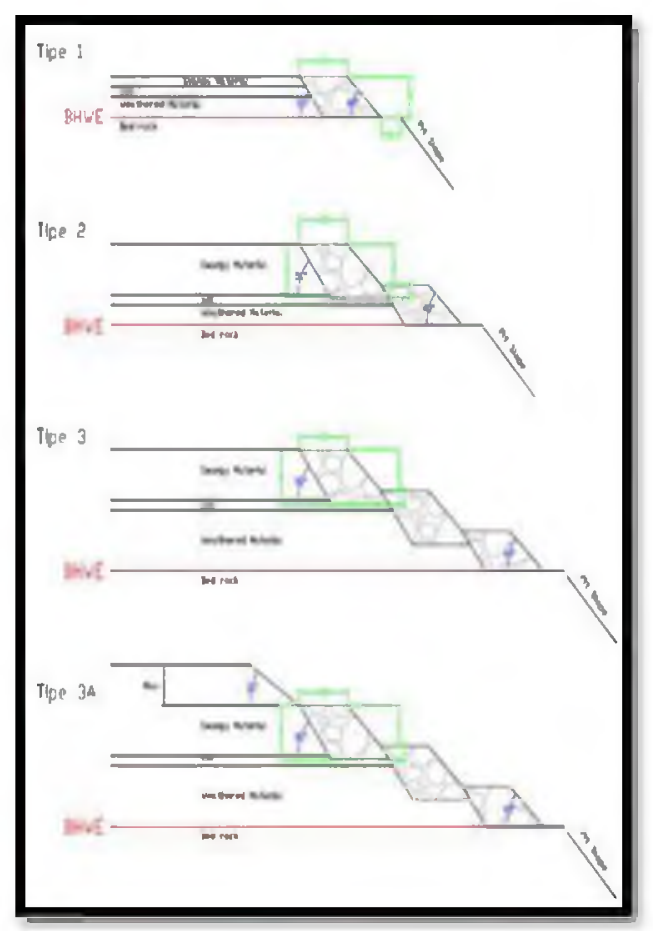

Gambar 4. Benching Counter weight Methode (Sumber: Bagian Pit Operation)

\section{Metode Sayatan Penampang}

Batubara merupakan cadangan dengan tingkatan endapan homogenitas yang tinggi, maka perhitungan cadangan dapat diterapkan dengan metode ini. Pada masing-masing penampang akan diperoleh luas batubara dan tanah penutup. Volume batubara dan tanah penutup dapat diketahui dengan mengalikan luas terhadap jarak pengaruh penampang tersebut. Metode sayatan penampang berdasarkan dua pedoman yaitu, pedoman rule of gradual changes dan rule of nearest point.

1. Pedomanrule of gradual changes

Masing-masing penampang akan dipeoleh luas batubara dan luas tanah penutup. Volume batubara dan tanah penutup dapat diketahui dengan mengalikan luas terhadap jarak pengaruh penampang tersebut. (Gambar 5)

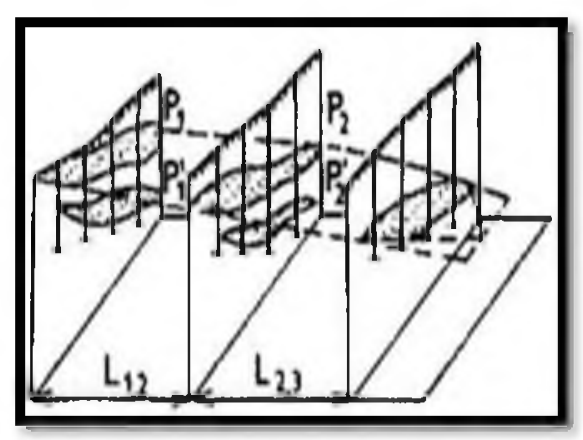

Gambar 5. Rule Of Gradual Changes (Sumber: Abdul Rauf, 1998)

Dengan rumus:

$$
\begin{aligned}
& V_{C} \text { atau } V_{O B}=\frac{S_{1}+S_{2}}{2} \times L \\
& W_{c}=V_{c} \times \gamma
\end{aligned}
$$


Keterangan:

$$
\begin{array}{ll}
\mathrm{V}_{\mathrm{C}} & =\text { Volume batubara }\left(\mathrm{m}^{3}\right) \\
\mathrm{V}_{\mathrm{OB}} & =\text { Volume } \text { overburden }\left(\mathrm{m}^{3}\right) \\
\mathrm{S}_{1}, \mathrm{~S}_{2} & =\text { Luas penampang }\left(\mathrm{m}^{2}\right) \\
\mathrm{L} & =\text { Jarak penampang }(\mathrm{m}) \\
\mathrm{W}_{\mathrm{c}} & =\text { Tonase batubara }(\mathrm{ton}) \\
\gamma & =\text { Densitas }\left(1,3 \text { ton } / \mathrm{m}^{3}\right)
\end{array}
$$

2. Pedoman rule of nearest point

Pada metode ini, setiap blok ditegaskan oleh sebuah penampang yang sama panjang ke setengah jarak untuk menyambung sayatan (Gambar 6)

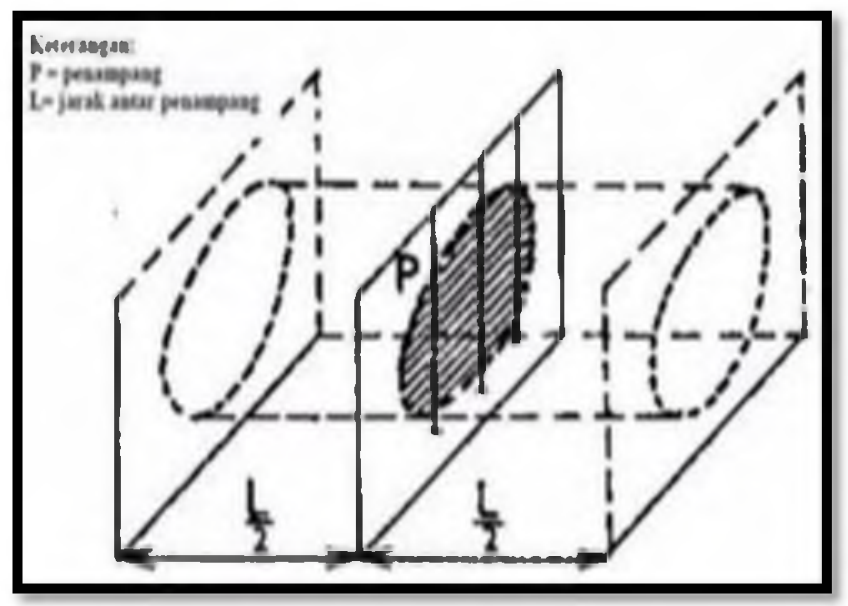

Gambar 6. Rule Of Nearest Point (Sumber: Abdul Rauf, 1998)

Dengan rumus:

$$
\begin{aligned}
& V_{C} \text { atau } V_{O B}=A \times L \\
& W_{C}=V_{C} \times \gamma
\end{aligned}
$$

\section{Keterangan:}

$$
\begin{array}{ll}
\mathrm{V}_{\mathrm{C}} & =\text { Volume batubara }\left(\mathrm{m}^{3}\right) \\
\mathrm{V}_{\mathrm{OB}} & =\text { Volume } \text { overburden }\left(\mathrm{m}^{3}\right) \\
\mathrm{A} & =\text { Luas penampang }\left(\mathrm{m}^{2}\right) \\
\mathrm{L} & =\text { Jarak penampang }(\mathrm{m}) \\
\mathrm{W}_{\mathrm{c}} & =\text { Tonase batubara }(\mathrm{ton}) \\
\gamma & =\text { Densitas }\left(1,3 \text { ton } / \mathrm{m}^{3}\right)
\end{array}
$$

\section{Nisbah Pengupasan/Stripping Ratio}

Nisbah pengupasan adalah perbandingan antara volume lapisan tanah penutup yang akan digali dengan jumlah tonase batubara yang akan diambil. (Gambar 7).

Pehitungan dengan rumus:

$$
S R=\frac{V_{O B}}{W_{c}}
$$


Keterangan:

$$
\begin{aligned}
& \mathrm{SR}=\text { Stripping ratio }(\mathrm{BCM} / \text { ton }) \\
& \mathrm{V}_{\mathrm{OB}}=\text { Volume overburden }\left(\mathrm{m}^{3}\right) \\
& \mathrm{W}_{\mathrm{c}}=\text { Tonase batubara (ton) }
\end{aligned}
$$

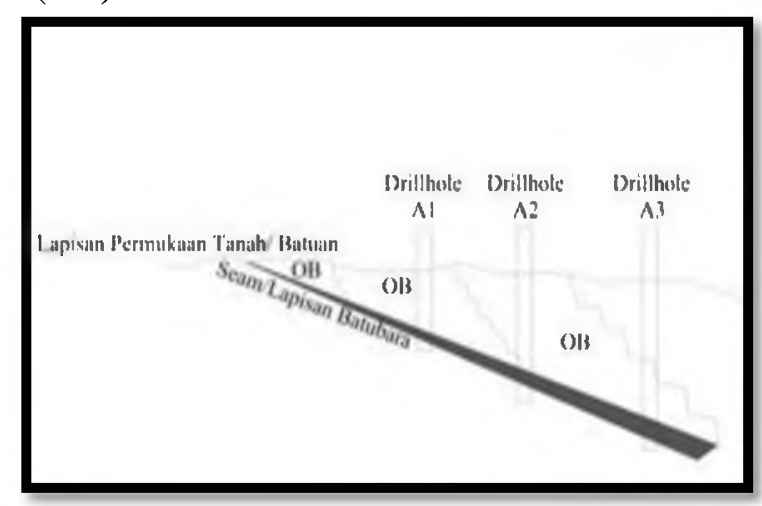

Gambar 7. Perbandingan $O B$ dan Coal

\section{Persentase Kesalahan / Error}

Cadangan terkira dan cadangan terbukti yang kuantitasnya dihitung dari pengukuran nyata, misalnya dari pemboran, singkapan sedangkan kadarnya diperoleh dari hasil analisis contoh. Jarak titik-titik pengambilan contoh sangat jelas. Struktur, jenis, komposisi, kadar, ketebalan, kedudukan dan kelanjutan endapan mineral dapat ditentukan dengan tepat.

Menurut MC. Kelvey, untuk perhitungan cadangan terkira dan terbukti faktor kesalahan tidak boleh lebih dari $20 \%$.

Perhitungan dengan rumus:

$$
\% \text { Eror }=\frac{\text { (Hasil estimasi terbesar }- \text { Hasil estimasi terkecil) }}{\text { Hasil estimasiterkecil }} \times 100 \%
$$

\begin{tabular}{|c|c|c|c|}
\hline PEVIIPANG & IUAS PEXAIPAYG & IAKAK & VOLLAE FENAMAVG \\
\hline Ant' & 2,482110 & \multirow{2}{*}{30.650} & \multirow{2}{*}{$109,705.760$} \\
\hline 8.8 & 1,349809 & & \\
\hline B-B & $1,849.802$ & \multirow{2}{*}{50.510} & \multirow{2}{*}{$95,015.778$} \\
\hline$C-C$ & $1,912.451$ & & \\
\hline$\overline{C S C}$ & $1,912.451$ & \multirow{2}{*}{ \$9.738 } & \multirow{2}{*}{$95,952.228$} \\
\hline DD & $1,944,305$ & & \\
\hline D.D & 1.94305 & \multirow{2}{*}{18244} & \multirow{2}{*}{$107,286.032$} \\
\hline$E-E^{\prime}$ & $2,503.358$ & & \\
\hline E.E' & $2,503.338$ & \multirow{2}{*}{100.000} & \multirow{2}{*}{$261,463.723$} \\
\hline$\overline{F+F}$ & $2,725.936$ & & \\
\hline F-F & $2,725.936$ & \multirow{2}{*}{102.305} & \multirow{2}{*}{287,006365} \\
\hline G-G & $2,884.862$ & & \\
\hline$G-G^{\prime}$ & $2,884.862$ & \multirow{2}{*}{$\$ 7.928$} & \multirow{2}{*}{$1+7,642.127$} \\
\hline H.H & 3.276 .139 & & \\
\hline $\mathrm{BH} H$ & $3,276.135$ & \multirow{2}{*}{36.571} & \multirow[t]{2}{*}{$203,540.116$} \\
\hline $1-8$ & 3,990490 & & \\
\hline If & $3,990.1900$ & \multirow{2}{*}{98.514} & \multirow{2}{*}{$\$ 31,410992$} \\
\hline I.J & $\$, 767879$ & & \\
\hline J-5 & $\$, 767879$ & \multirow{2}{*}{96.160} & \multirow{2}{*}{$489,976.811$} \\
\hline K-K & 5,331172 & & \\
\hline \multirow{2}{*}{\multicolumn{3}{|c|}{$\begin{array}{l}\text { TOLLANE TOTAI BATRBARA } \\
\text { TONASE }\end{array}$}} & $2,226,5999.953$ \\
\hline & & & $2,894,9799939$ \\
\hline \multicolumn{3}{|c|}{ MINLVG RECOIERY SEAYY } & $2,605,1219,4,4$ \\
\hline
\end{tabular}

\section{Perhitungan Cadangan}

1. Berdasarkan Pedoman Rule Of Gradual Changes (Tabel 1)

Tabel 1. Rule Of Gradual Changes 
$\mathrm{V}_{\mathrm{c}}=2.226 .599,953 \mathrm{~m}^{3}$

$\mathrm{W}_{\mathrm{c}}=2.894 .579,938$ ton

$\mathrm{MR}=2.894 .579,938 \times 90 \%$

$$
=2.605 .121,305 \text { ton }
$$

2. Berdasarkan Pedoman Rule Of Nearest Point (Tabel 2)

Tabel 2. Rule Of Nearest Point

\begin{tabular}{|c|c|c|c|}
\hline PEVALIPAIIG & LUAS PEYAVPANG & JARAK & IOLLAE PELALIPANG \\
\hline A.A' & $2,482.110$ & 50.650 & $125,718.887$ \\
\hline B-B' & 1.849 .805 & 50.650 & $93,692.633$ \\
\hline$C_{-C}$ & $1,912.451$ & 49.758 & $95,159.742$ \\
\hline D-D' & 1.94 .305 & 49.758 & $9,74,718$ \\
\hline E.E' & $2,503.338$ & 100.000 & $250,333.830$ \\
\hline E-F & $2,725.936$ & 100.000 & 272.993 .620 \\
\hline$G-G^{\prime}$ & $2,884.862$ & $\$ 7.928$ & 138365.676 \\
\hline H.H & 3276.135 & $\$ 7.928$ & $157,018.579$ \\
\hline I.I & $3,990.490$ & 98.514 & $393,119.152$ \\
\hline $2-2$ & $\$, 767.879$ & 98.514 & $469,02.832$ \\
\hline $\mathrm{X}-\mathrm{K}^{\prime}$ & $5,331 .+72$ & 96.160 & $512,674,376$ \\
\hline \multicolumn{3}{|c|}{ YOLLME TOTAL BATLBARA } & $2,605,024.045$ \\
\hline \multicolumn{3}{|c|}{ TONASE } & $3,386,531,258$ \\
\hline \multicolumn{3}{|c|}{ IILLIG RECOIERY SELUI } & $3,047.878 .132$ \\
\hline
\end{tabular}

$$
\begin{aligned}
& \mathrm{V}_{\mathrm{c}}=2.605 .024,045 \mathrm{~m}^{3} \\
& \mathrm{~W}_{\mathrm{c}}=3.386 .531,258 \text { ton } \\
& \mathrm{MR}=3.386 .531,258 \times 90 \% \\
& =3.047 .878,132 \text { ton }
\end{aligned}
$$

\begin{tabular}{|c|c|c|c|}
\hline PENAIYPANG & LUAS PEVAVPANG & JARAK & TOLLME PENAMPANG \\
\hline A.d & 1.590280 & \multirow{2}{*}{30650} & \multirow{2}{*}{50,961046} \\
\hline B.-B' & 1.590808 & & \\
\hline B.-B' & $1,590.808$ & \multirow{2}{*}{50.510} & \multirow{2}{*}{$81,354,017$} \\
\hline C.C & 1,630496 & & \\
\hline C.C & $1.630 \mathrm{dg}$ & \multirow{2}{*}{49.758} & \multirow{2}{*}{$83,497.034$} \\
\hline D-D' & 1,725629 & & \\
\hline D-D' & 1,725629 & \multirow{2}{*}{48244} & \multirow{2}{*}{94,662136} \\
\hline E.E & 2,198678 & & \\
\hline E.E. & 2.198678 & \multirow{2}{*}{100000} & \multirow{2}{*}{$202,090,410$} \\
\hline F.F & 1.843131 & & \\
\hline$F-F$ & 1,843131 & \multirow{2}{*}{102.305} & \multirow{2}{*}{$141,125.497$} \\
\hline $0-0^{\prime}$ & 915780 & & \\
\hline 0.6 & 915.786 & \multirow{2}{*}{$\$ 7,928$} & \multirow{2}{*}{25,236899} \\
\hline $\mathrm{HH}$ & 138.160 & & \\
\hline H.H' & 138160 & \multirow{2}{*}{96.971} & \multirow{2}{*}{$9,4+3.824$} \\
\hline 1.5 & 135.002 & & \\
\hline i. 5 & 123.002 & \multirow{2}{*}{98911} & \multirow{2}{*}{$3 \downarrow, \$ 07.903$} \\
\hline 15 & $\$ 73.529$ & & \\
\hline 8.2 & 973.329 & \multirow{2}{*}{$\% 160$} & \multirow{2}{*}{$60,819.609$} \\
\hline $\mathrm{K}-\mathbf{K}$ & $691+38$ & & \\
\hline \multicolumn{3}{|c|}{ IOLLAE TOTAL PEAT GAMBUT } & $811,318,011$ \\
\hline
\end{tabular}

\section{Perhitungan Overburden}

1. Berdasarkan Pedoman Rule Of Gradual Changes)

a. Material Gambut (Tabel 3)

Tabel 3. Material Gambut

$$
\mathrm{V}_{\text {gambut }}=811.218,008 \mathrm{~m}^{3}
$$


b. Material Softclay (Tabel 4)

Tabel 4. Material Softclay

\begin{tabular}{|c|c|c|c|}
\hline PENALIPAY & LUAS PENAIPAYYG & $\mathrm{JAR}+\mathrm{K}$ & \multirow{3}{*}{$257,94,229$} \\
\hline$A-A^{\prime}$ & $9,814.917$ & \multirow{2}{*}{50.650} & \\
\hline B-B' & $\$, 370.413$ & & \\
\hline B-B' & 4.370.413 & \multirow{2}{*}{50.510} & \multirow{2}{*}{203,149210} \\
\hline$c-c^{-}$ & 3.673 .508 & & \\
\hline$\frac{C C}{D N}$ & 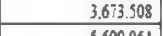 & +9.998 & \multirow{2}{*}{233,180201} \\
\hline$D \cdot D$ & $9,699.064$ & & \\
\hline$\frac{D \cdot D^{\prime}}{E \cdot E^{\prime}}$ & $\begin{array}{l}9.699 .061 \\
9592018\end{array}$ & 48.24 & $367,887.312$ \\
\hline$\frac{E}{E \cdot E^{\prime}}$ & 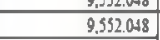 & \multirow{2}{*}{100.000} & \multirow{2}{*}{$849,272,430$} \\
\hline$F \cdot \bar{F}$ & $7,433 . .001$ & & \\
\hline$F=F$ & $\begin{array}{l}7, \$ 33.401 \\
\end{array}$ & \multirow{2}{*}{ 102.305 } & \multirow{2}{*}{$767,312.123$} \\
\hline$\frac{G-G^{\prime}}{G g^{\prime}}$ & $\begin{array}{l}7,567.081 \\
\end{array}$ & & \\
\hline $\begin{array}{l}G-G \\
H \cdot H\end{array}$ & $\frac{7,567.031}{9,874.078}$ & 47.928 & $274,175.915$ \\
\hline H.FT & $3,874.078$ & \multirow{2}{*}{36.571} & \multirow{2}{*}{$241,363.172$} \\
\hline I. -8 & $\begin{array}{l}4.639 .039 \\
\end{array}$ & & \\
\hline I. [ & $\begin{array}{l}1,699.039 \\
\end{array}$ & \multirow{2}{*}{ 98.51. } & \multirow{2}{*}{$550,855 . \$ 773$} \\
\hline J.J & $6,524.254$ & & \\
\hline I. .3 & 6.5224254 & \multirow{3}{*}{96.160} & \multirow{2}{*}{668,728906} \\
\hline $\mathbf{K}-\mathbf{K}$ & $7,38.417$ | & & \\
\hline & TOTAL SOFTCLAY & & 1.413 .869274 \\
\hline
\end{tabular}

$\mathrm{V}_{\text {soffclay }}=4.413 .869,274 \mathrm{~m}^{3}$

Mixing $=4.413 .869,274 \times 50 \%$ $=2.206 .934,637 \mathrm{~m}^{3}$

c. Material Hardclay (Tabel 5)

Tabel 5. Material Hardclay

\begin{tabular}{|c|c|c|c|}
\hline PEYAMPAVG & LUAS PENAMPAYG & JARAK & VOLLME PENAANPAVG \\
\hline$A+A^{\prime}$ & $14,898.121$ & 30690 & 799.369 .832 \\
\hline$\frac{B-B^{\prime}}{B-B^{\prime}}$ & $\frac{16271168}{16271.68}$ & & \\
\hline C.C & $17,055.583$ & 50.510 & 811,674673 \\
\hline c.c & 17.055 .983 & 10759 & 8902970361 \\
\hline D.D & 15.915 .896 & & $820,09 . .216$ \\
\hline D.D & 15.915 .896 & 18244 & $863,160.153$ \\
\hline $\begin{array}{l}\frac{E-E^{\prime}}{E^{\prime}-E^{\prime}} \\
\end{array}$ & $\frac{19.867 .213}{19.867213}$ & & \\
\hline$\frac{E-E^{\prime}}{F-F}$ & $\frac{19.867 .213}{23.855547}$ & 100.000 & $2,186,138.000$ \\
\hline F-F & $23,855.9577$ & 107305 & 2161648006 \\
\hline G. $\sigma^{\prime}$ & $18,403.363$ & & \\
\hline G-G & $18,+03.365$ & 17.928 & 757,295207 \\
\hline$\frac{H \cdot H}{H \cdot H}$ & $\frac{13,198.004}{13,198.004}$ & & \\
\hline $\mathrm{I}-\mathrm{T}$ & 12831.270 & 56.571 & 736251.027 \\
\hline I.T & 12.831 .270 & 98514 & 1292913677 \\
\hline $7-2$ & 12.604 .986 & & \\
\hline$\frac{\pi}{2}$ & $12,604,986$ & 96.160 & $1,229,428.053$ \\
\hline$\frac{\text { K.K }}{\text { VOLL] }}$ & \begin{tabular}{|r}
$12,965.481$ \\
NIE TOTAL HARDCI.A
\end{tabular} & & $11,638.177 .066$ \\
\hline
\end{tabular}

$\mathrm{V}_{\text {Hardclay }}=11.638 .77,066 \mathrm{~m}^{3}$

2. Berdasarkan Pedoman Rule Of Nearest Point

a. Material Gambut (Tabel 6)

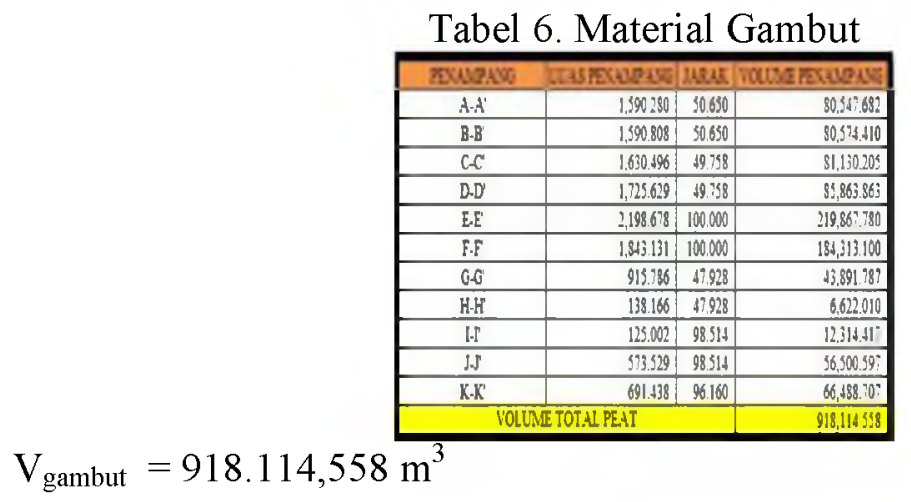


b. Material Softclay (Tabel 7)

Tabel 7. Material Softclay

\begin{tabular}{|c|c|c|c|}
\hline PENALPANG & LLAS PEAAIIPANG & JARAK & VOLLAE PENALIPANG \\
\hline$A-A^{\prime}$ & 5,814947 & 50.650 & $294,527.050$ \\
\hline B.B & $4,370.413$ & 50.650 & $221,361.408$ \\
\hline$C-C^{\prime}$ & 3,673508 & 49.758 & 182,786391 \\
\hline D-D' & 5.699 .064 & 49.758 & $283,574.012$ \\
\hline$E \cdot E^{\prime}$ & $9,552.048$ & 100.000 & $955,204.780$ \\
\hline $\mathrm{F} \cdot \mathrm{F}^{\prime}$ & $7,433.401$ & 100.000 & $743,340.080$ \\
\hline G-G' & $7,567.081$ & 47.928 & $362,675.039$ \\
\hline H-H' & 3,874078 & 47.928 & $185,676.99 !$ \\
\hline I. & $4,659.039$ & 98.514 & $458,980.578$ \\
\hline J. 1 & 6.524 .254 & 98.514 & $6+2,730.368$ \\
\hline $\mathrm{K} \cdot \mathrm{K}^{\prime}$ & $7,384.417$ & 96.160 & $710,085.539$ \\
\hline \multicolumn{3}{|c|}{ VOLLAE TOTAL SOFTCLAY } & $5,040,942.037$ \\
\hline
\end{tabular}

$$
\begin{aligned}
& \mathrm{V}_{\text {sotfclay }}=5.040 .942,037 \mathrm{~m}^{3} \\
& \text { Mixing }=5.040 .942,037 \times 50 \% \\
&=2.520 .471,018 \mathrm{~m}^{3}
\end{aligned}
$$

\begin{tabular}{|c|c|c|c|}
\hline PENAIIPANG & LLAS PENAMPANG & JARAK & VOLLME PENAIPANG \\
\hline$A \cdot A$ & $14,898.121$ & 50650 & 754.589 .849 \\
\hline B-B & $16,271+68$ & 50.650 & $824,149.854$ \\
\hline C.C & $17,055.583$ & 49.758 & $848,651.689$ \\
\hline D.D' & $15,915.896$ & $\$ 9.758$ & 791.943 .173 \\
\hline E.E' & $19,867.213$ & 100.000 & $1,986,721.300$ \\
\hline$F \cdot F$ & 23,855547 & 100000 & $2,385,554.720$ \\
\hline G-G & $18,403.365$ & 47928 & 882,036463 \\
\hline $\mathrm{H} \cdot \mathrm{H}^{\prime}$ & 13,198004 & 47.928 & $632,553.945$ \\
\hline I. $\Gamma$ & 12.831 .270 & 98514 & $1,264.059 .723$ \\
\hline J.2 & $12,604.986$ & 98514 & $1,241,767.630$ \\
\hline$K^{K}-K^{\prime}$ & $12,965,48 !$ & $96: 60$ & $1,246,760.614$ \\
\hline \multicolumn{3}{|c|}{ VOLLME TOTAL HARDCLAY } & $12,858,788.961$ \\
\hline
\end{tabular}

c. Material Hardclay (Tabel 8)

Tabel 8. Material Hardclay

$$
\mathrm{V}_{\text {Hardclay }}=12.858 .788 .961 \mathrm{~m}^{3}
$$

\section{Nisbah Pengupasan/Stripping Ratio}

1. Berdasarkan Pedoman Rule Of Gradual Changes

$\mathrm{W}_{\mathrm{c}}=2.605 .121,944$ ton

$\mathrm{V}_{\mathrm{OB}}=19.070 .199,007 \mathrm{BCM}$

$$
\begin{aligned}
S R & =\frac{19.070 .199,007}{2.605 .121,944} \\
& =7,32(7,32 \mathrm{BCM}: 1 \text { ton })
\end{aligned}
$$

2. Berdasarkan Rule Of Nearest Point

$\mathrm{W}_{\mathrm{c}}=3.047 .878,132$ ton

$\mathrm{V}_{\mathrm{OB}}=21.338 .316,574 \mathrm{BCM}$

$S R=\frac{21.3047 .316,574}{3.047 .878,132}$

$=7(7 \mathrm{BCM}: 1$ ton $)$ 


\section{XIII.Persentase Kesalahan}

$$
\begin{aligned}
\text { \%eror } & =\frac{3.047 .878,132-2.605 .121,944}{2.605 .121,944} \times 100 \% \\
& =16,9 \%
\end{aligned}
$$

\section{Faktor Kesalahan}

1. Bentuk topografi yang berbeda yang berpengaruh pada perhitungan. Kekurangan metode cross section adalah sulit membaca topografi yang sangat kompleks.

2. Adanya perbedaan perlapisan dan parting dalam satu titik bor.

3. Pengambilan contoh ketebalan batubara yang kurang detail.

4. Penarikan garis sayatan dengan jarak yang berbeda karena titik bor yang tidak grid

5. Perhitungan ini dengan aspek geologi yang masih rendah.

\section{Kesimpulan}

1. Total tonase batubara:
a. Rule Of Gradual Changes adalah 2.605.121,944 ton
b. Rule Of Nearest Point adalah 3.047.878,132 ton

2. Volume overburden:
a. Rule Of Gradual Changes adalah 19.070.199,007 $\mathrm{m}^{3}$
b. Rule Of Nearest Point adalah 21.338.316,574 $\mathrm{m}^{3}$

3. Nilai stripping ratio sebagai berikut:
a. Rule Of Gradual Changes adalah 7,32 BCM : 1 ton

b. Rule Of Nearest Point adalah 7 BCM : 1 ton

4. Persentase kesalahan dari perhitungan adalah $16,9 \%$

5. Hasil estimasi cadangan terkira pada daerah PIT DE

\section{Saran}

1. Hasil perhitungan dari kedua metode, maka disarankan hasil estimasi terkecil cadagan batubara terkira terkecil yang dipakai sebagai perhitungan produksi

2. Perhitungan cadangan terkira ini dapat digunakan metode pembanding yang lebih canggih untuk ditingkatkan menjadi cadangan terbukti.

3. Dilakukan kajian kelayakan dari segi ekonomi dan teknis untuk meningkatkan menjadi cadangan terbukti.

\section{DaftarPustaka}

1. Rauf, Abdul. 1998, "Perhitungan

Cadangan Endapan Mineral", FakultasTeknologi Mineral, Jurusan Teknik Pertambangan, Universitas Pembangunan Nasional, Yogyakarta

2. Soejitno, H. Purus, "Eksplorasi

Batubara Untuk Studi Kelayakan", Direktorat Batubara 1995

3. Simatupang, Marangin dan Sigit, Soetaryo. ISBN 979-8012-66-6, "Pengantar Pertambangan Indonesia". 
4. Sukandarrumidi, 2008. "Batubara

Dan Gambut", Cetakan Ketiga Universitas Gajah Mada.

5. Standar Nasional Indonesia

Amandemen I SNI 13-5014-1998, "Klasifikasi Sumberdaya dan Cadangan"

6. Partono, P., M. Bambang

Sugeng., 1993. "Tambang Terbuka" Lembaga Pengabdian Pada Masyarakat dan Jurusan Teknik Pertambangan Institut Teknologi Bandung. 
A.A. Inung Arie Adnyano 